\title{
Lutein and cognition in children
}

In a recent paper Mulder et al. ${ }^{(1)}$ analysed the relationship between measurements of cognition and dietary and plasma lutein levels in children. Mulder et al.'s correlational study was based on previous observations that lutein is found in the brain ${ }^{(2)}$ and has been linked to cognition and central nervous system function in adults ${ }^{(3)}$. Unlike previous work in adults, however, Mulder et al. found no relationship between their assessments of cognition and lutein measured in blood and diet. On this basis, they conclude that any effect of lutein on cognition in children is likely to be 'subtle' and difficult to separate from other covariates. Although this very well may be true, the data and results provided by Mulder et al. cannot be used as the basis for such a conclusion.

First, their study population was particularly well nourished, which would have reduced their ability to detect associations based on restricted range. For example, in a large US sample (US National Health and Nutrition Examination Survey; NHANES), the average intake of lutein for 4- to 8-year-olds was 311 (SD 474) $\mu \mathrm{g} / \mathrm{d}^{(4)}$. Based on the same assessment ( $24 \mathrm{~h}$ recall), average intake of lutein in the Mulder et al. sample was nearly four times higher (mean intake was $2130 \mu \mathrm{g} / \mathrm{d}$ when assessed by their FFQ). As the authors note, this suggests 'higher intakes of lutein among children in the present study.... Like many food components, the largest functional effects of lutein may be the most significant for those with relative deficiency ${ }^{(5)}$. Since the authors did not supply the range of scores on the Kaufman Assessment Battery (KABC) or Peabody Picture Vocabulary Test (PPVT), it is impossible to evaluate whether similar statistical issues (restricted range) apply to their cognitive scores.

Another significant limitation of the study was the selection of plasma and diet as a biomarker for lutein in brain. Some of the most compelling data on the role of lutein and brain function come from studies that were not cited by the authors ${ }^{(6-10)}$. Those studies directly measured lutein in central nervous system tissue. The technology exists to measure lutein and zeaxanthin non-invasively within retinal tissue (there referred to as macular pigment; MPOD) ${ }^{(11)}$. This can even be done in premature infants ${ }^{(12)}$ and has been done in children ${ }^{(13)}$. Concentrations in the retina, being part of the central nervous system, are highly correlated with concentrations of lutein in the brain ${ }^{(14)}$. In contrast, diet and serum (as used by Mulder et al.) are known to not correlate well with central nervous system levels of lutein. For example, serum lutein tends to only explain about $7 \%$ of the variance in retinal lutein; dietary intake only explains about $4 \%{ }^{(15)}$. It is unlikely that the plasma or dietary lutein assessments that Mulder et al. conducted predicted variation in central levels of this pigment in children. Indeed, as Mulder et al. note, when using the FFQ, dietary intake of lutein only explained about $10 \%$ of the variation in serum lutein: repeated immediate recall of intake (three $24 \mathrm{~h}$ food diaries) only explained $25 \%$ of the variance. Past studies have shown that serum lutein and zeaxanthin are only moderately predictive of serum lutein and zeaxanthin assessed at a separate time ${ }^{(16)}$. If serum lutein cannot strongly predict itself, it seems unlikely to be able to predict variation in the brain, especially in children.

The type of cognitive testing the authors performed (the $\mathrm{KABC}$ and PPVT) are very broad-ranging tests of developmental status. Such tests are probably not the most sensitive means of measuring the effects of diet on brain development. For example, recent studies on young college studies have shown significant effects of lutein when using more direct and atomistic assessments of neural activity such as visual processing speed ${ }^{(17)}$ or neuroimaging ${ }^{(18)}$.

We share the authors' view on the importance of nutrition on optimal brain development. It is unlikely, however, that the Mulder et al. study will help inform our understanding of whether lutein has an influence on brain function during this critical period. As the authors note, this population was at 'low risk' for 'nutrient inadequacy' and therefore enhancing cognition beyond average seems an unreasonable goal. Perhaps a better framing of the conclusion of this study would be that higher lutein intake in a nourished sample of 
children is unrelated to cognitive enhancement when measured using relatively coarse cognitive assessments.

There are no conflicts of interest to report.

Billy R. Hammond

Brain and Behavioral Sciences The University of Georgia Athens, GA 30602-3013 USA email bhammond@uga.edu

\section{References}

1. Mulder KA, Innis SM, Rasmussen BF, et al. (2014) Plasma lutein concentrations are related to dietary intake, but unrelated to dietary saturated fat or cognition in young children. J Nutr $S_{c i} \mathbf{3}$, e11.

2. Craft NE, Haitema TB, Garnett KM, et al. (2003) Carotenoid, tocopherol, and retinol concentrations in elderly human brain. J Nutr Health Aging 8, 156-162.

3. Johnson EJ (2014) Role of lutein and zeaxanthin in visual and cognitive function throughout the lifespan. Nutr Rev 72, 605-612.

4. Johnson EJ, Maras JE, Rasmussen HM, et al. (2010) Intake of lutein and zeaxanthin differ with age, sex, and ethnicity. $J A m$ Diet Assoc 110, 1357-1362.

5. Wong JC, Engles M, Wooten BR, et al. (2010) Macular pigment: visual effects of deficiency. Invest Ophth Vis Sci 51, 1288.

6. Renzi LM, Bovier ER \& Hammond BR Jr (2013) A role for the macular carotenoids in visual motor response. Nutr Neurosci 16, 262-268.

7. Renzi LM, Dengler MJ, Puente A, et al. (2014) Relationships between macular pigment optical density and cognitive function in unimpaired and mildly cognitively impaired older adults. Neurobiol Aging 35, 1695-1699.

8. Feeney J, Finucane C, Savva GM, et al. (2013) Low macular pigment optical density is associated with lower cognitive performance in a large, population-based sample of older adults. Neurobiol Aging 34, 2449-2456.

9. Nolan JM, Loskutova E, Howard AN, et al. (2014) Macular pigment, visual function, and macular disease among subjects with Alzheimer's disease: an exploratory study. J Alzheimers Dis (epublication ahead of print version 2 July 2014).

10. Vishwanathan R, Iannaccone A, Scott TM, et al. (2014) Macular pigment optical density is related to cognitive function in older people. Age Ageing 43, 271-275.

11. Hammond BR, Wooten BR \& Smollon B (2005) Assessment of the validity of in vivo methods of measuring human macular pigment optical density. Optometry Vision Sci 82, 387-404.

12. Bernstein PS, Sharifzadeh M, Liu A, et al. (2013) Blue-light reflectance imaging of macular pigment in infants and children. Invest Ophth Vis Sci 54, 4034-4040.

13. Bour LJ, Koo L, Delori FC, et al. (2002) Fundus photography for measurement of macular pigment density distribution in children. Invest Ophth Vis Sci 43, 1450-1455.

14. Vishwanathan R, Neuringer M, Snodderly DM, et al. (2013) Macular lutein and zeaxanthin are related to brain lutein and zeaxanthin in primates. Nutr Neurosci 16, 21-29.

15. Curran-Celentano J, Hammond BR, Ciulla TA, et al. (2001) Relation between dietary intake, serum concentrations, and retinal concentrations of lutein and zeaxanthin in adults in a Midwest population. Am J Clin Nutr 74, 796-802.

16. Apgar J, Makdani D, Sowell AL, et al. (1996) Serum carotenoid concentrations and their reproducibility in children in Belize. Am J Clin Nutr 64, 726-730.

17. Bovier ER, Renzi LM \& Hammond BR (2014) A double-blind, placebo-controlled study on the effects of lutein and zeaxanthin on neural processing speed and efficiency. PLOS ONE 9, e108178.

18. Duda D, Mewborn C, Lindbergh C, et al. (2014) Brain activity associated with verbal learning and recall in older adults and its relationship to lutein and zeaxanthin concentrations. Arch Clin Neuropsych 29, 506 . 